\section{Don Peppers}

is a founding partner of Peppers \& Rogers Group and an acclaimed author. He is in high demand as both a speaker and a management adviser with Fortune 500 executives and entrepreneurs seeking to identify their most valuable customers, increase customer satisfaction and improve ROC. He is a popular voice among editors and the media, both online and in print, and is the co-author, with Martha Rogers, of a series of international bestsellers that have collectively sold over a million copies in 15 languages.

Martha Rogers, Ph.D has been recognised for the past decade as one of the world's leading experts on customer-based business strategies and growing customer value. Dr Rogers is an acclaimed author, a worldclass speaker and a founding partner of Peppers \& Rogers Group.

Keywords: Return on Customer, customer equity, metric, trust, optimisation, short term
Don Peppers

Peppers \& Rogers

Carlson Court

116 Putney Bridge Road London SW15 2NQ, UK Tel: +44 (0)20 88753100 E-mail: dpeppers@1 to1.com

\section{Return on Customer: A new metric of value creation - Return on investment by itself is not good enough}

\author{
Don Peppers and Martha Rogers \\ Received: 26 January 2006
}

\begin{abstract}
Marketers are being assailed from all quarters with respect to accountability for their initiatives. But virtually all the financial measures being used, from return on investment (ROI) to return on marketing investment (ROMI), have a fatal limitation: each assumes there is an infinite supply of customers and prospects. In fact, however, customers and prospects are limited in number. They are a scarce productive resource - even scarcer than capital for most businesses. No business can create value without a customer, and different customers create value at different rates. If marketing's job is to create the maximum possible value for a business, then it should employ a metric of success that gauges how much value is created per customer available, rather than how much value is created per dollar invested. Return on Customer, or ROC, is a metric designed for that purpose. ROC incorporates not just the profit generated by a customer in the current period, but also any positive or negative changes in the customer's lifetime value during the period. A firm relying on ROC will actually make different - and more managerially and financially beneficial - decisions than it would make by relying solely on ROI. ROC should be maximised from among the alternatives that exceed a firm's investment hurdle rate. To do this, a firm must earn the trust of its customers.
\end{abstract}

\section{Rationing the customer resource}

Company $\mathrm{X}$ is a multi-line insurance company selling auto, property, life and health insurance through a network of its own agents who work exclusively for Company $\mathrm{X}$. The agents each have authority to sell any one of the firm's products to their customers. To protect agent profitability and maintain order within the distribution channel generally, Company $\mathrm{X}$ does not allow any of its agents to solicit clients from any of its other agents. The firm's different products generate very different amounts of profit for the company. Customers who buy life insurance from the firm, for instance, tend to have much higher lifetime values than customers who buy auto insurance. Not only is life insurance a higher-margin product for Company X, but life insurance customers are not as likely to switch out their policies, generate fewer service costs and are less prone to fraud.

But not all agents sell all products with the same energy - not because 
they are not encouraged to do so by the company, but because some agents are simply less comfortable selling certain products than they are selling others. This can be due to an agent's background and expertise, or perhaps her book of business is heavily skewed to one line or another, so that she is simply more familiar with the characteristics and nuances of a particular line. An agent may naturally develop specialisations in certain product lines, and it is almost impossible for her to sell all of Company X's products with an equal level of enthusiasm and effectiveness.

Now what is the cost, to Company X, of a particular agent who does an excellent job of selling auto and property insurance almost exclusively? The agent has a fine track record of new customer acquisition, as well as a large book of business. She has even been winning sales awards, and the company's ROI on commissions paid to her is very good. But every time she recruits a brand new customer for auto or property insurance, that customer becomes less likely to buy any other type of insurance from Company $\mathrm{X}$, because the agent is unlikely to suggest other types of insurance to a customer herself, but no other agents will be allowed to solicit, either. This agent knows she can build a bigger book of business, faster, simply by acquiring more customers for auto or property insurance rather than spending time and energy learning how to sell health or life insurance to her existing customers. But although the agent is better served, the customer is not, and neither is the company's bottom line. The fact is, all of this agent's new auto and property customers would be more valuable to the company if they had life insurance as well as auto and property, and many might be more valuable with life insurance alone.

\section{'Using up' customers to produce revenue}

\section{A bigger problem in smaller markets}

Likewise, the company would probably be of greater service to customers, many of whom would prefer to have all their insurance with one trustworthy provider. But because this agent serves as the gatekeeper, Company X has to 'use up' a whole customer every time it sells another auto or property policy to this agent's customers.

This kind of dilemma is faced by many businesses in many different industries. Customers and prospective customers are limited in number, so if a company wants to maximise the value it creates for its shareholders it must maximise the value it creates from each available customer. This can easily create organisational conflicts, as it may for Company $\mathrm{X}$, and the usual solution to this kind of problem boils down to some sort of customer rationing - in effect, limiting the number of new customer acquisitions or sales transactions permitted to different channel members, or partitioning the customer base to protect the interests of different sales and marketing actors.

In smaller national markets the scarcity of customers will be even more pronounced, and can be expected to distort business decisions to an even greater extent. It is one thing to say that a US company may have 'only' 100 million customers for its product or service, but quite another if a Belgian company, or a Spanish company, 'only' has 1 million customers, or perhaps 20 million. The smaller the market, in fact, the more any business will have to confront the problem of customer scarcity.

Unfortunately, simply measuring the cost applied to a customer initiative against the returns generated will not enable a firm to optimise 


\section{ROI assumes supply of customers is infinite}

its treatment of a finite quantity of customers and prospects. When there are only a limited number of customers and prospects, every customer for whom value is not maximised represents a lost opportunity that is gone forever; it is value that could have been captured but was not, and it cannot later be replaced from an unlimited supply of other opportunities or even from additional customers.

\section{Maximising ROI is not the right solution}

ROI (return on investment) and ROMI (return on marketing investment) can be helpful, but these metrics of value creation can also be demonstrated to be inadequate in many situations. Although most companies do not realise it, nearly every firm runs out of customers before it runs out of cash to invest in them. When a company prioritises its initiatives by maximising ROI, however, it is implicitly assuming that the supply of cash is limited, while the supply of customers is infinite.

To take a very simple example, suppose you have two different marketing initiatives available to you, generating different financial results.

- Treatment A requires a $\$ 4$ investment per customer to create $\$ 6$ in total value. This means that each customer creates $\$ 2$ in net new value after a $\$ 4$ investment, for an ROI of 50 per cent.

- Treatment B requires a $\$ 12$ investment per customer to create $\$ 16$ in total value, so it generates $\$ 4$ in net new value per customer on a $\$ 12$ investment, yielding an ROI of just 33 per cent.

The ROI-maximising company will choose Treatment A every time, because it has a higher ROI. Every dollar invested in Treatment A yields $50 \notin$ in net profit, compared with only $33 \phi$ in net profit per dollar invested in Treatment B.

But what if your firm had only, say, 100,000 current and potential customers altogether, no matter what? If this were the case, then with Treatment B you could create a total of $\$ 400,000$ in net new value from those 100,000 customers, while with Treatment A you could only create $\$ 200,000$ of net new value (Table 1). Clearly, choosing Treatment B, which is not the highest-ROI alternative, would actually produce more shareholder value for your firm! And what if, instead of 100,000 customers, you had 10 million? Or 50 million? Would the answer be any different?

In the case of Company $\mathrm{X}$, the insurance firm, it is possible that the

Table 1: Creating customer value

\begin{tabular}{|ccccccc|}
\hline & $\begin{array}{c}\text { Investment } \\
\text { per } \\
\text { customer } \\
(\$)\end{array}$ & $\begin{array}{c}\text { Value } \\
\text { created per } \\
\text { customer } \\
(\$)\end{array}$ & $\begin{array}{c}\text { Net new } \\
\text { value per } \\
\text { customer } \\
(\$)\end{array}$ & $\begin{array}{c}\text { Return on } \\
\text { investment } \\
(\%)\end{array}$ & $\begin{array}{c}\text { Total } \\
\text { customers }\end{array}$ & $\begin{array}{c}\text { Shareholder } \\
\text { value } \\
\text { created } \\
(\$)\end{array}$ \\
\hline Treatment A & 4 & 6 & 2 & 50 & 100,000 & 200,000 \\
Treatment B & 12 & 16 & 4 & 33 & 100,000 & 400,000 \\
\hline
\end{tabular}


ROI achieved from recruiting new customers exclusively for auto and property insurance is higher than the ROI achieved by recruiting new customers for life insurance. This would be true if, for instance, commissions paid for new auto customers are lower relative to the amount of profit earned, or if it is simply more expensive to recruit new life insurance customers. So Company X may find that the money it invests in the agent dedicated to selling auto and property policies actually yields a higher ROI than money invested in other agents. It takes more customers to earn this higher ROI, but this is invisible to Company $\mathrm{X}$ because it is not tracking the 'cost' of consuming more of its customer resource.

\section{Return on Customer measures the real efficiency of value creation}

Return on Customer (ROC) ${ }^{1}$ measures the rate at which a business is able to create value from any given customer. Simply stated, ROC is the sum of the firm's current-period profit from a customer, plus any change in the customer's value, divided by the customer's value at the beginning of the period:

$$
\mathrm{ROC}=\frac{\begin{array}{c}
\text { Profit from customer in current period } \\
+ \text { change in the customer's value in period }
\end{array}}{\text { Customer's value at beginning of the period }}
$$

'Profit' in this equation is more useful to us if we express it in cash flow terms, and a customer's value should be thought of as the customer's lifetime value (LTV), which is the net present value of future cash flows expected from the customer.

ROC and ROI are both financial metrics designed to track the efficiency with which value is created. ROI measures how much value is

Measuring the efficiency of value creation

\section{Measuring both short-term and long- term value creation} created relative to the amount of money employed to create it, while ROC measures it relative to the amount of customer equity employed to create it. This is an important point, because companies require capital and customers to create value. Ironically, while they carefully measure their return on capital invested, they do not measure their return on customers used, despite the fact that for most businesses operating in mature Western economies customers would be considered an even scarcer input.

When customers are scarcer than capital a business will create more shareholder value by maximising the return it generates on the customers and prospects available, rather than by maximising its return on the capital available.

Note that the ROC metric also includes an explicit recognition of the two different ways customers create value for a business: by buying things currently, and by changing currently their intention or likelihood of buying in the future. The economic effect of a change in the likelihood of future business can be thought of as a change in the customer's previously expected LTV, and such changes represent value gained or lost currently, even if the actual cash effects are not felt until later.

Suppose, for instance, a valuable customer were to call you with a complaint, but for some reason your firm did not handle the complaint 


\section{Royal Bank of Canada tracks LTV changes}

very well. The customer remained angry, hanging up the phone in disgust. The moment the customer hung up the phone, your company lost some of its value. The customer's likelihood of doing business with you in the future declined significantly, so his LTV declined. The customer may actually continue to do buy from you for some time, and might even be under contract to do so, but nevertheless the total amount of future cash flow you can expect to generate from this particular customer has been reduced, and this reduction occurred today, with the customer's phone call. So with that phone call your company actually lost some of its value, in the same way that your stock price would drop today if your CEO were to predict lower earnings sometime in the future.

Whether you measure it today or not, whether you hold someone accountable today or not and whether or not you balance the sales your employees make today with the future value it 'costs' to make those sales, your company's overall value is affected currently by changes in a customer's intention or likelihood of doing business with you in the future.

Of course, customer LTV has been written about substantially in the past, and is not a new concept to marketing. Many companies evaluate their customer acquisition programmes today by estimating the amount of new customer LTV acquired, rather than simply counting the number of new customers. Despite all the attention paid to LTV in the past, however, tracking the likely changes in a customer's LTV that result from a company's current actions is a relatively new idea, and only a few forward-thinking companies are making an effort to do so.

Royal Bank of Canada, for instance, has been focused on customer relationships in its retail banking business for more than a decade now, and became a 'best practice' case study in this area years ago. ${ }^{2}$ One of the secrets of the bank's success is the fact that it constantly monitors the behavioural cues in its customer database in order to optimise current income results against likely changes in LTV for individual customers. Royal Bank of Canada optimises what it calls 'overall efficiencies', a term that includes both current income and LTV changes. One example of a policy change based on maximising overall efficiencies has to do with 'courtesy overdraft limits'. This product is now provided for the vast majority of consumer customers, rather than just heavy-hitters. Each customer's overdraft limit is set based on that particular customer's overall relationship with the bank. In general, anyone who has been a customer for at least 90 days, has a low-risk credit score and has made at least one deposit in the last month will have some level of overdraft protection. Not only does this enhance each customer's experience with the bank, but it actually increases the bank's efficiency during the cheque-clearing process, reducing the number of write-offs and allowing account managers to focus on sales activities. Overall, since 1997 the bank has increased the profitability of its average client by 13 per cent and increased the number of high-value clients by 20 per cent. $^{3}$

Royal Bank of Canada knows that how it treats a customer today affects not only the profit it will make on the customer in the immediate future, but also the customer's long-term likelihood of continuing to do 


\section{Maximising ROC is an optimisation problem}

business with the bank, or of doing more business or recommending other customers. Companies that do not recognise the long-term value customers are capable of creating for them often focus exclusively on maximising short-term results, and this can have a harmful effect on the overall level of value created by customers. There is a trade-off between current-period results and long-term value which requires a company to balance its actions carefully. Too much emphasis on aggressive selling may simply cannibalise future customer business, or worse - it might irritate some customers to the point that they are less likely to buy in the future. Too much emphasis on future value, on the other hand, risks incurring excessive costs while not returning enough in profit, even over the long term.

Thus, maximising ROC is really an optimisation problem, involving a balancing act between taking current income and preserving or increasing future customer value. It might be easier to visualise the problem by thinking about the kind of balancing act that farmers must manage when they try to maximise the overall value of their farming operations. A farmer could plant the richest, most productive cash crop on all his acreage every year and make a great deal of money in the short term, but his land would soon burn out. The more prudent farmer would ensure the long-term productivity of his land by practising conservation - rotating his crops, fertilising, aerating the soil and leaving some land fallow each year. This is a more costly way to farm, but the farmer is ensuring that his land will remain productive for many years.

In farming, land is the scarce resource. For a business, customers are the scarce resource. A business must make the most of its customers in the same way that a farmer must make the most of his land. A prudent farmer must strike the best possible balance between overusing his land and underusing it. A prudent manager must strike the same type of balance with customers. It is worthwhile remembering that farmers face short-term temptations, just as business executives do. In any given year a prudent farmer can always make more money by forgoing conservation that year. Smart farmers never do that, of course, because it is selfdefeating and destructive.

But business executives do it all the time. One 2004 survey revealed that meeting short-term earnings expectations is such an urgent need in publicly held firms that three out of four senior executives said their company would actually give up economic value in exchange for doing so. More than half of the executives said they would 'delay starting a project to avoid missing an earnings target'. Four out of five executives said they 'would defer maintenance and research spending to meet earnings targets'. ${ }^{4}$

ROC, because it explicitly takes account of the way in which a firm's current actions will affect the future value of customers, serves as a significant deterrent to this type of mismanagement.

\section{ROC applies to prospects, too}

The ROC metric can be applied to problems involving not just current customers, but prospects as well. That is, just as every company has only 


\section{Prospects have probability-weighted LTVs}

a finite number of customers, it has only a finite number of prospects as well, so it is important to create as much value from each prospective customer as possible. Largely because they are limited in number, prospects actually do have a current value. Consider two companies, for instance, each with the same number of current customers, and each gaining the same level of revenue and profit from those customers. The first company has identified a large number of prospective customers, while the second company has no identified prospects. Which company is worth more? Which firm would you rather invest in? It is always worth more to have a prospect than not to have one.

But how much is a prospect worth, actually? What is the value, today, of a prospective customer you do absolutely no current business with, and with whom you may never do business? One way to think about it is to estimate the customer's LTV if he were to become a customer, and then multiply this figure times his likelihood of becoming a customer.

Because prospects have probability-weighted LTVs, you can generate a higher ROC on them not just by targeting your customer acquisition campaigns at higher-LTV prospects, but also by taking actions that increase the likelihood of particular prospects becoming customers. If your business-to-business firm conducts a free seminar for prospective customers, the prospects who elect to attend have almost certainly increased their likelihood of becoming customers. If your consumer marketing firm offers free samples, the consumers who take the samples are more likely to become customers. In each case, your marketing programme actually created current value, in the form of the increased probability that certain non-customers would actually become customers. And because you need to know whether it makes sense to run a seminar for non-customers, or to give samples away, you must consider the current values of these customers you do not yet have. Increasing the value of prospective customers is a legitimate and time-honoured business activity.

In thinking about the total value a company creates for its shareholders, therefore, it is important not to disregard potential customers. ${ }^{5}$

\section{ROC equals total shareholder return}

At the enterprise level, when considered across both customers and prospects, ROC is mathematically equivalent to total shareholder return (TSR). Calculated retrospectively, TSR is a precisely defined financial term referring to the overall return a shareholder earns from owning a company's stock over some period of time. ${ }^{6}$ According to one financial authority: 'Total Shareholder Return (TSR) represents the change in capital value of a listed/quoted company over a period (typically one year or longer), plus dividends, expressed as a plus or minus percentage of the opening value. ${ }^{7}$

This definition is based on what a shareholder's actual cash flow would be if he were to buy stock at the beginning of the period and sell it at the end. The shareholder gets cash dividends during the period, and by the end of the period there may also have been some up or down change in the capital value of the stock itself. This definition relies on a retrospective calculation. As a shareholder you can always tally the exact 


\section{Customer equity defined}

\author{
Verizon Wireless \\ achieves 70 per cent \\ ROC
}

return you experienced during some previous period, provided your share price is set by the market. ${ }^{8}$

If you are trying to estimate your TSR prospectively, however, then you obviously cannot rely on the price of the stock at some point in the future. Instead, you must estimate the likely change in the value of your company, or your stock, during this future period. In a perfect world, a publicly traded firm's market-driven 'capital value' would equal the discounted value of its expected future cash flow, plus or minus any existing assets or liabilities. ${ }^{9}$ There is no way to prove or disprove this, because no one really knows what any company's discounted cash flow is going to be in the future. Nevertheless, it is widely accepted that the market price of a public company's stock at any point in time reflects the marginal investor's best guess as to the company's discounted future cash flow value.

To understand the ROC equals TSR argument, all one need do is start with the premise that all value created by any company's business operation ${ }^{10}$ must come from its customers at some point. If the discounted cash flow value of an operating business is created entirely by customers, then its discounted cash flow is composed of the individual LTVs of all its current and future customers. When all of a firm's current and future customer LTVs are added together, the resultant quantity is called 'customer equity', and for an operating firm customer equity will exactly equal the firm's total discounted future cash flow from operations.

But ROC, when calculated for an enterprise considering its whole customer base (including prospects), is the sum of the firm's currentperiod cash flow and any change in the company's underlying customer equity, divided by customer equity at the beginning of the period. In other words, ROC is simply a different way to express TSR, when that quantity is to be calculated prospectively.

During the period 2002 - 2004, Verizon Wireless (a joint venture between Verizon and Vodafone) grew its customer base from 29.4 million handsets in use to 43.8 million. During the same period the company's monthly customer attrition rate was reduced from 2.6 per cent to 1.3 per cent, substantially increasing the LTVs of its customers. While Verizon Wireless reported $\$ 13.7 \mathrm{bn}$ in operating earnings during this period, it also added to its customer equity by $\$ 13.9 b n$ - so it actually created more than twice as much value for shareholders as was reflected in its financial statements. (To accomplish this, Verizon doubtless had to make some trade-offs by investing in services and programmes that cost money in the short run in order to keep more customers in the long run.) About 40 per cent of this increase in customer equity was attributable to the new customers acquired during the period, but 60 per cent was attributable to the increase in average customer LTV as a result of the increased customer retention rate. ${ }^{11}$

Verizon Wireless generated an average annual ROC of roughly 70 per cent during this three-year period. What this means, in actuality, is that by focusing on maximising the value created by its customers Verizon Wireless was able to create shareholder value every year that amounted to about two-thirds of its actual value as an operating business at the beginning of that year. ${ }^{12}$ 


\section{ROC improves predictability of earnings}

The truth is, Verizon Wireless's four-year surge in value creation was probably a one-time event for the company, because the more customer churn has been reduced the harder it becomes to reduce it further. But other wireless firms throughout the world face opportunities every bit as rich as this, and for the most part they have failed to take advantage of them. In fact, if anything there is strong evidence that many mobile telecom companies are running in the opposite direction, chipping away at their customer equity as they compete fiercely to acquire new customers at any cost - even when it means acquiring customers with lower and lower LTVs. ${ }^{13}$

It is important to recognise, also, that while TSR can only really be applied at the enterprise level, ROC is a metric that breaks the economic value created by a business into smaller, customer-specific units, all the way down to the level of specific individual customers. ROC calculations do not rely on changes in share price, but if your shares are publicly traded then stock price can still provide an important additional reference point for validating your firm's total customer equity. Investors, moreover, pay a premium for predictability, and ROC should improve this. When assessing the likely future cash flow of a business for purposes of valuing it, a typical investment analysis might rely on a few dozen data points market growth trends, competitive initiatives, economic conditions, industry situation and so forth. But every trend line begins with today's numbers, so small deviations in these 'initial conditions' can generate huge perturbations in a company's stock price. This is certainly one reason why so many companies are so single-minded in their attention to meeting the short-term expectations of financial analysts. In addition to such trend lines, ROC will arm a company (and its investors) with hundreds of additional data points, which should have the effect of dramatically improving the predictability of a firm's financial results. It is also likely to help investors better understand the actual business and economic factors behind those results.

\section{Using ROI and ROC together}

If customers are the scarcest resource for a company, to create the maximum possible shareholder value in any given period a firm must generate the highest possible return on this scarce resource during that period. It can only create the most value possible for its shareholders by creating as much value as possible from the customers and prospects it has available, because a company's universe of customers and prospects represents the very outer boundary of its potential for the operating business. Once it has employed its total resource of customers and prospects, it is powerless to create any more value.

But just because customers are scarcer than capital does not mean capital has no value. It costs money to use money. As long as a firm is willing to pay the cost it may have access to a virtually unlimited supply of capital, but it must pay the cost. So a company should never undertake an initiative in which the ROI is less than its cost of capital, no matter how good the ROC may be on the initiative.

In essence, a firm's cost of capital should be thought of as a kind of 


\section{ROI as a 'hurdle rate'}

'hurdle rate' by which to judge resource-consuming initiatives. Only initiatives that have an ROI above a company's hurdle rate should be considered, but considering all such initiatives, the most financially beneficial will be those that have the highest ROC. It is certainly possible, however, that a high-ROC initiative might actually generate a lower-thanacceptable ROI.

Consider the hypothetical Treatment A and Treatment B example used earlier, summarised in Table 1. Now suppose Treatment B, rather than requiring a $\$ 12$ investment per customer to create $\$ 16$ in value, had required $\$ 60$ per customer to generate $\$ 64$ in value. If this were the case it would still be possible to create more value across the available customer base by choosing Treatment B, which continues to generate the same $\$ 4$ in net value per customer as it did before, while Treatment A generates just $\$ 2$ per customer in net value. In other words, even with this heavy level of required investment, Treatment B, when applied across all available customers, will still create more total value than Treatment A (Table 2). But instead of 33 per cent, the ROI on Treatment B would now be less than 7 per cent (a $\$ 60$ investment is required to generate just $\$ 64$ in value), and this would almost certainly be lower than whatever ROI hurdle rate the company requires before an investment can be considered. ${ }^{14}$

Figure 1 is a scatter graph that shows both ROI and ROC for an assortment of different possible actions for Company Y. ROC increases along the horizontal axis, while ROI increases along the vertical axis. After eliminating duplications, conflicts and trivial data points, the firm has calculated all feasible combinations of initiatives with respect to all identified groups of customers and prospects available. Each dot on the scatter graph, in other words, represents the overall ROI and ROC calculated for a different combination of initiatives, and each combination involves virtually all the company's customers and prospects. The scatter graph portrays the universe of possible ROI-ROC combinations available to Company Y.

It should be obvious that no combination of initiatives should be considered if its ROI is lower than the firm's hurdle rate for making capital investments. But from the set of all possible combinations of customer initiative that generate an ROI higher than the hurdle rate, Company Y should choose a course of action that generates the highest possible ROC. Thus the circled set of dots on the upper right side of the scatter graph represents the most promising set of choices for Company $\mathrm{Y}$, in terms of creating overall shareholder value.

Table 2: Combining ROC with ROI

\begin{tabular}{|ccccccc|}
\hline & $\begin{array}{c}\text { Investment } \\
\text { per } \\
\text { customer } \\
(\$)\end{array}$ & $\begin{array}{c}\text { Value } \\
\text { created per } \\
\text { customer } \\
(\$)\end{array}$ & $\begin{array}{c}\text { Net new } \\
\text { value per } \\
\text { customer } \\
(\$)\end{array}$ & $\begin{array}{c}\text { Return on } \\
\text { investment } \\
(\%)\end{array}$ & $\begin{array}{c}\text { Total } \\
\text { customers }\end{array}$ & $\begin{array}{c}\text { Shareholder } \\
\text { value } \\
\text { created } \\
(\$)\end{array}$ \\
\hline Treatment A & 4 & 6 & 2 & 50 & 100,000 & 200,000 \\
Treatment B & 60 & 64 & 4 & 7 & 100,000 & 400,000 \\
\hline
\end{tabular}




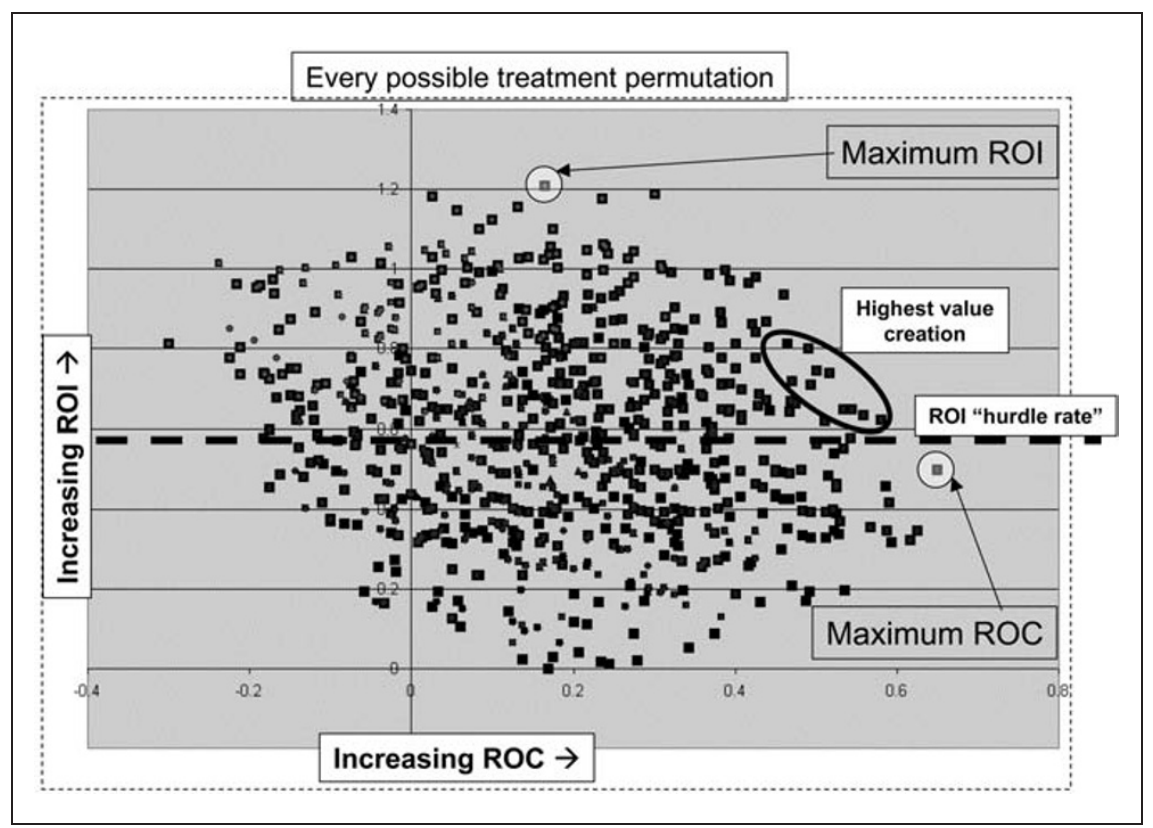

Figure 1: A universe of possible ROI-ROC combinations

Of course, the investment hurdle rate employed by a company might not be in the form of a minimum ROI. Some firms, for instance, require that any investment must achieve payback within a set time period, or that the profit generated by a dollar of capital invested must exceed some higher amount within three years and so forth. But regardless of how a firm ensures that its investments provide returns that are comfortably higher than its cost of capital, the economic principle remains the same: to maximise the total amount of shareholder value created, a firm should maximise its ROC from among the alternatives that exceed its cost of capital.

\section{A word about customer trust}

Even though ROC is just a different metric of value creation, it has an important philosophical implication for your business in terms of how you relate to your customers: to maximise the overall return generated by customers (including long-term value as well as current profit) you must earn your customers' trust.

To see why this is so, consider your value proposition with a customer: you give the customer something of value and in exchange the customer gives you something of value. Over the long term, you can expect to receive the most value from a customer at more or less the same time that your customer is getting the most value from you. But what value does the customer get?

Obviously, product quality, price and service all factor in to the customer's current purchase decision. But assuming you are roughly on a par with your competitors, there must be other factors as well. To maximise your ROC you must balance both the current profit from a customer and the long-term change in a customer's value. But does the 


\section{Customer advocacy generates trust}

\section{USAA balances short-term and long- term value creation}

customer have a similar perspective, as he considers whether to do business with you both now and in the future? The customer, too, must weigh long-term as well as short-term factors, assessing the value he gets from his relationship with you. And for the customer, such a relationship will be of the most value when he feels he can trust you to respect his interests as if they were your own.

Research shows that companies with the best reputations for customer advocacy (ie acting in the interest of the customer) get the most additional business from customers. This is completely logical and understandable, for when a customer perceives you to be acting in his own interest, then he benefits every time he deals with you. Thus he will go out of his way to deal with you more, because his interest is well served by doing so.

A 2004 Forrester survey ${ }^{15}$ of 6,000 North American financial services consumers found that 'customer advocacy', defined by Forrester as 'the perception by customers that a firm is doing what's best for them and not just for the firm's bottom line', was the single 'best indicator of whether financial services companies are able to achieve cross-sell success to a customer base'. Forrester's summary of the research went on to say 'Firms that score highest on the customer advocacy scale, such as USAA and Edward Jones, are considered the most for future purchases of products and services.'

The fact is that maximising the return you generate on a customer and maximising the customer's trust are co-dependent tasks, because what they actually represent are two different views of the customer value proposition - your perspective and the customer's. The more a customer trusts you to act in his interest, the more overall value he will get from you, both in the current transaction and in potential future transactions as well. So the more you try to act in the customer's interest, the more value that customer is likely to provide to you, considering both current and future business.

At USAA the philosophy that informs all customer interaction is 'Treat the customer the way you would want to be treated if you were the customer.' According to long-time CEO Robert McDermott, now retired, it was this philosophy more than anything else that enabled him to turn the company around during the 1970s and 1980s, converting it from a stodgy, bureaucratic and largely incompetent insurance firm into what became a virtual icon of great customer service. At a practical level, applying this kind of philosophy requires a firm sometimes to give up an opportunity for immediate profit in order to earn the longer-term trust and loyalty (and increased LTV) of the customer involved. In USAA's case, every time a sales associate recommends a less expensive alternative to a customer who would have been happy to spend more, the firm gives up a current profit opportunity, but it probably increases that customer's LTV by an even greater amount.

Common sense tells us that things such as customer trust, product and service quality, customer satisfaction and willingness to recommend must all be related to higher customer LTVs. When a firm takes an action today that increases trust or customer satisfaction, it is simply logical that the LTVs of the customers affected will increase. ROC measures the rate of 
that increase, providing a straightforward financial rationale for investors and others who might need convincing.

This is, in fact, the 'flip side' of the ROC idea. ROC is not just a better metric of corporate value creation. It is also a philosophy of doing business. Sooner or later, any firm that focuses on maximising ROC will find that earning the trust of its customers is a vital step in the process.

Of course, acting in the genuine interest of customers is an old and time-honoured method for creating a successful business. This is not a new concept. The only thing new is that we now have a metric - ROC able to quantify the benefits of this business philosophy.

\section{References}

1. Return on Customer ${ }^{\mathrm{SM}}$ and $\mathrm{ROC}^{\mathrm{SM}}$ are registered service marks of Peppers \& Rogers Group, a division of Carlson Marketing.

2. Royal Bank of Canada deserves its own book for its innovative thinking, culture of customercentricity, focused management and serving as a world-class example of the business case for building customer value on purpose. See Peppers, D. and Rogers, M. (1999) The One to One Manager: Real-World Lessons in Customer Relationship Management, Currency/Doubleday, New York, pp. 121-129.

3. The details here on Royal Bank of Canada are from Burrows, C. (2004) 'Managing customer value', presentation to the Executive Education Program, Fuqua School of Business, Duke University, 13 September; and from a subsequent telephone interview with Burrows and Mark Vermeersch at Centra Bank.

4. The main point of the 2004 executive survey of more than 400 senior financial executives by Duke University and the University of Washington is this: ironically, the Sarbanes-Oxley Act, enacted by the US government in the wake of scandals involving managed earnings and financial manipulations, and imposing tough new restrictions on corporations' ability to adjust their accounting to manage their earnings, has probably resulted in increased willingness on the part of executives to sacrifice value. Because a firm is no longer able to manipulate its accounting to smooth its earnings, 78 per cent of the executives surveyed said they would actually change policies and give up long-term value in exchange for smoothing out short-term earnings. See Dalesio, E. P. (2004) 'Study: Executives sacrifice shareholder value to please Street', press release, Associated Press State \& Local Wire, 9 February; Plender, J. (2004) 'Anglo-American lunacy', Financial Times, 16 February, p. 20.

5. Note also that because potential customers have a real, probabilistic value that can be calculated, when a firm adds a new customer from a prospect pool the actual value created is not equal to the entire LTV of the new customer, but only the difference between that value and the customer's former value as a prospect.

6. When talking about 'shareholder return' one is really talking about the rate at which an enterprise is creating value for its owners. But this term is used as loosely and generically as possible. If you are in business for yourself, you are the shareholder for your own enterprise. Shareholder value matters, whether the shareholder meetings are big, formal affairs or held over the kitchen table.

7. The definition of TSR came from Value-Based Management.net, available at www.valuebasedmanagement.net/methods_tsr.html.

8. If your company is privately held rather than publicly traded, calculating TSR is more difficult because you first need to calculate an objective value for your shares, both at the beginning of the period and at the end.

9. Cash is king, of course. See McGuinness, B. (2000) Cash Rules. Learn and Manage the Seven Cash Flow Drivers for your Company's Success, Kiplinger, USA. The point is that cash and capital value are approximately the same thing.

10. In considering a firm's 'business operation' this paper is purposely disregarding capital structure and thinking only of the firm's actual business as an operating business. There are a few exceptions to the statement that customers create all value, but not many. Asset sales can create value, perhaps, but such gains are not usually considered part of operating income — and in any 
case, the asset buyer could often be considered a type of 'customer'. Rents and royalties could also be considered to come from customers in many cases.

11. Financial and operating statistics for Verizon Wireless are drawn from publicly reported financial documents. The calculation of ROC uses a 10 per cent financial discounting rate and makes some simplifying assumptions that, if anything, tend to understate its value. Assumptions include operating margin of 25 per cent throughout the period; revenue per user, margin and attrition likelihood are uniform across the customer base; and customer acquisition costs are exactly offset by new LTVs of customers added throughout the period.

12. In doing these calculations, rather than separately trying to value Verizon Wireless's future customers as a part of the calculation of its customer equity, the simplifying assumption has been made that the firm's average customer acquisition cost, which is a reduction of current earnings, is more or less equal to the average LTV of the customers acquired during the period.

13. See Braff, A., Passmore, W. J. and Simpson, M. (2003) 'Going the distance with telecom customers', McKinsey Quarterly, No. 4, available at www.mckinseyquarterly.com.

14. Strictly speaking a company's cost of capital is an annual rate, but for argument's sake one can assume that Treatments A and B each require a full year of investment in order to realise the benefit.

15. See Forrester's report on customer service among financial institutions, which has USAA at the very top. Doyle, B. (2004) 'What satisfies financial services consumers', The Forrester Report, 2 June. These quotes are from Forrester (2004) 'New research unveils financial services winners and losers in customer advocacy ranking', press release, 10 June. 